\title{
SOBRE AVARICIA Y LUJO DE ENCOMENDEROS EN EL OCTAVO REMEDIO DE BARTOLOMÉ DE LAS CASAS
}

\author{
ON THE GREED AND LUXURY OF ENCOMENDEROS IN \\ BARTOLOMÉ DE LAS CASAS'S EIGHTH REMEDY
}

VIRGINIA ASPE

Universidad Panamericana, México

Recibido: 17/07/2019 Aceptado: 23/09/2019

\section{RESUMEN}

El texto analiza las razones que da Bartolomé de las Casas en el tratado Octavo remedio con el objetivo de probar que la clave argumental del dominico se sustenta en la codicia y lujo de los encomenderos. Para Las Casas, ni por ley natural ni por derecho de gentes es legítimo desposeer a los naturales de sus propiedades ni cobrarles más impuestos de los que legítimamente pueden imponerles las leyes de Castilla y la Corona española. Pero tales argumentos, acordes con el criterio económico de autores salmantinos, son rebasados y radicalizados por Las Casas en la medida en que desplaza el tema hacia el lujo y la codicia de los encomenderos. En el Octavo remedio cita textos escriturales y de ética aristotélica para señalar que la libertad de los indios conlleva derechos inalienables de propiedad y dominio. Por estos argumentos el Octavo remedio cuestiona las encomiendas de facto en la Nueva España. Las Casas parte de la tradición salmantina pero radicaliza su discurso al argumentar a la luz de pasajes veterotestamentarios ante los problemas de exclusión; con ello instaura un discurso económico emancipador y libertario en América que centra la atención en el escándalo de los lujos y la codicia de los poderosos.

Palabras clave: América, comunidad, economía, Escuela de Salamanca, indios, justicia, libertad. 


\section{ABSTRACT}

This text analyzes the reasons given by Bartolomé de las Casas in the treatise Eight Remedy with the aim of proving that the Dominican's argumentative focus consists of encomenderos' greed and luxuries. For Las Casas, neither natural law nor law of nations provide a legitimate justification for depriving natives of their properties or for raising taxes for them beyond what the laws of Castile and the Spanish Crown had already stipulated. However, these arguments, in compliance with the economic criteria of Salamancan authors, are exceeded and radicalized by Las Casas in so far as he focuses on encomenderos' greed and luxury. The Eighth Remedy quotes biblical writings and Aristotelian texts on ethics in order to emphasize that natives' freedom implies inalienable rights of property and possession. Because of this, the Eighth Remedy puts into question the very encomiendas that were taking place in New Spain. Las Casas comes from a Salamancan school of thought, but he radicalizes his discourse by employing passages of the Old Testament in the face of the problem of exclusion, thus establishing an emancipating and liberating economic discourse in America which focuses on the opulence and greed of the ruling class.

Keywords: Americas, community, economy, School of Salamanca, indigenous people, justice, freedom.

\section{INTRODUCCIÓN E HIPÓTESIS}

En esta investigación me propuse rastrear dos términos de moral económica que desarrolla Bartolomé de las Casas en el tratado Octavo remedio: la usura y la avaricia ${ }^{1}$. Bartolomé de las Casas nace en Sevilla en 1484 y muere en Madrid en 1566. De familia noble, estudia con Nebrija y Palencia en la Universidad de Alcalá donde lee a Virgilio y Cicerón; posteriormente pasa a la Universidad de Salamanca, donde estudia derecho y aprende las doctrinas peripatéticas explicadas por los escolásticos. En las aulas conoce el derecho romano, algunas doctrinas canónicas de tendencia ultramontana que enfatizan el poder del papa y el derecho de los reyes delegado por el sumo pontífice, pero es hasta su estancia

1 Ésta es la edición que seguiré: Bartolomé de las Casas, "Octavo remedio", en Tratados (Ciudad de México: FCE, 1997), 643-837. Empero, cfr. también los tratados en Bartolomé de las Casas, Obras completas. (Sevilla: Alianza, 1989-1999). Debe subrayarse que los dominicos de Andalucía cuentan con esta edición crítica de las obras completas de Las Casas: Obras completas (Madrid: Alianza, 1988-1996), ya que autores como Enrique Díaz Araujo en Las Casas visto de costado. Crítica bibliográfica sobre la Leyenda Negra (Madrid: Fundación Francisco Elías de Tejada y Erasmo Pèrcopo, 1995) argumentan que los dominicos no han hecho una edición crítica de las obras completas de Las Casas por la reprobación a sus tesis; esto es falso. 
en América y la toma del hábito dominico y renuncia de sus encomiendas entre los años 1511 y 1514 que profundiza sobre estos temas. La vida de Bartolomé de las Casas puede dividirse en un antes y después de estos sucesos a pesar de los claroscuros que la caracterizan. Sucesos claves en la vida del padre Las Casas son el fallido experimento social de Cumaná en 1520 y el frustrado plan de colonización pacífica en la avanzada española a tierra firme en 1522; su reflexión teórica posterior en 1523-1524 con la redacción de sus primeras obras (De único vocatione modo) y el inicio de la Historia de Indias (texto que continuará a lo largo de su vida); también su obispado en Chiapas en 1543, el viaje a España de 1547 con la consabida Disputa de Valladolid 1550-1551 y la posterior redacción e impresión de sus tratados filosóficos en 1552. El telón de fondo de la vida de Las Casas lo constituyen las Leyes de Indias (surgidas de las Leyes de Burgos de 1512), la bula Sublimis Deus 1537, las Nuevas Leyes de 1542, y la Disputa de Valladolid contra Ginés de Sepúlveda en 1550; este último hecho lo hizo replegarse al estudio y reflexión teórica de sus propuestas, dando lugar a la publicación de sus tratados filosóficos u obras de madurez $z^{2}$.

Las Casas tiene una vida llena de claroscuros por la peculiar circunstancia de su contexto y por el protagonismo público que promovió en la defensa indiana; estas particularidades le han seguido a lo largo de los siglos en que los pensadores se debaten para denostarlo o enaltecerlo. En esta investigación me aparto de tales interpretaciones, optando por un análisis internalista de los argumentos que expone en el Octavo remedio. Intento probar que Las Casas sigue las contribuciones básicas de la Escuela de Salamanca al tiempo que radicaliza su postura en el ámbito económico en razón de su experiencia americana, experiencia que no tuvieron Francisco de Vitoria y Domingo de Soto y que marca el vuelco lascasiano en su consideración de la economía ${ }^{3}$.

2 Se señalan tres etapas evolutivas en el padre Las Casas: la etapa juvenil de 1493-1524, la etapa crítica de 1524-1551, y el periodo de madurez de 1551-1561. Cfr. Valeria López Vela, Igualdad, libertad y legalidad. Reflexiones políticas sobre filosofia lascasiana. (Ciudad de México: Porrúa, 2014). Debe tenerse en cuenta que autores de la talla de Mauricio Beuchot Puente —en Estudios de historia y de filosofía en el México colonial (Ciudad de México: UNAM, 1991) — no incluyen a Bartolomé de las Casas como académico por no haber dado clases en la universidad. Empero, el texto de López Vela demuestra su contribución teórica y escolar más allá de esta circunstancia. Cfr. López Vela, ibidem., xvi y ss.

3 Cfr. Juan Belda Plans, La Escuela de Salamanca y la renovación de la teología en el siglo XVI. (Madrid: BAC, 2000), 922. Allí el autor clasifica al discurso novohispano como de "tercera generación" de la Escuela de Salamanca; amén de que yo siga dicha cronología, es sintomático que el autor separa a los pensadores americanos egresados de la Universidad de Salamanca, o miembros de dicha Escuela, de sus maestros. Belda Plans nos dice que esto se debió a que replantearon el discurso económico en América en razón de la experiencia y conocimiento particular que tuvieron por las necesidades del momento. 
Los textos de Bartolomé sobre el poder de los reyes son enfáticos respecto del predominio papal, aunque tiene conocimiento de los límites de su poder gracias a la influencia de Jean Charlier Gerson, al que cita; es importante señalar que la impronta del poder papal y del regio es definitiva en sus argumentaciones, que siguen la línea humanista de autores como Lucio Marineo Sículo y Pedro Mártir de Anglería, influencias importantes en el ideario lascasiano a pesar de no citarlos en los tratados de 1552. Sículo, humanista italiano, capellán y cronista en la corte de Fernando de Aragón, influye en el Renacimiento español, en especial en la Universidad de Salamanca; experto en lengua latina y griega, escribe un sumario de la vida de los Reyes Católicos, impronta que, como veremos en el tratado analizado, es definitiva en la mentalidad y convicciones de Las Casas ${ }^{4}$.

Por otro lado, es relevante en la obra de Las Casas, Pedro Mártir de Anglería: humanista e influyente asesor de los Reyes Católicos, consejero de Indias entre 1520 y 1526 , participa en campañas granadinas contra los moros en 1492 (en las que conoce a Cristóbal Colón), apoya a Carlos I en la revuelta de las comunidades de Castilla y se involucra en soluciones políticas. La revuelta comunera y la lucha contra moros y judíos serán temas subyacentes en el ideario lascasiano. En Décadas del Nuevo Mundo, Pedro Mártir informa (partes cuarta y quinta) sobre México y, al seguir las Cartas de relación de Hernán Cortés, presenta un ideal romanesco de los príncipes que será tema recurrente en Las Casas ${ }^{5}$; experimentos pacifistas sociales, como el de Cumaná de 1520, tuvieron a participantes de la revuelta comunera de Castilla que emigraron a América tras la derrota; al interpretar las propuestas lascasianas, hay que conocer estas circunstancias para ponderar adecuadamente el claroscuro de la época.

Del humanismo italiano, Las Casas bebe de textos de Bartolo Sassoferrato y Baldo Ubaldo, de los que toma el tema de la justificación de la independencia de las ciudades-Estado para el consentimento de pueblos sojuzgados estableciendo límites al poder del monarca. También sigue a Cicerón en cuanto a la persuasión política y la divulgación de las injusticias que señala ${ }^{6}$. Su humanismo es indudable y se aproxima al de Flandes con Erasmo de Rotterdam, tal y como Mauricio Beuchot y Marcel Bataillon han probado.

4 El texto lo publica Sículo en 1587, pero le antecedió la obra De Aragoniae eteoru rerum gestos libri de 1509.

5 Cfr. Pedro Mártir Anglería. The Discovery of the New World by Peter Martyr of Anghiera (Roma: IPZS, 2004), 373-393.

6 Cfr. David Brading, Orbe indiano. De la monarquía católica a la república criolla. 14921867 (Ciudad de México: FCE, 2003), 11-14 y 119. 
Es indispensable el seguimento de estas fuentes lascasianas para comprender su impronta salmantina y el desplazamiento que opera en el discurso. El seguimento de fuentes se debe a que Las Casas es deudor tanto de tradiciones clásicas latinas y de Aristóteles como del canonismo medieval y del humanismo, al tiempo que tiene una formacion tomista e incorpora pasajes del Antiguo Testamento, para elaborar un discurso novedoso en parte que adapta, responde y articula argumentaciones basadas en la experiencia directa de los problemas económicos de la administración colonial.

Como se sabe, el padre Las Casas es una personalidad polémica cuyo discurso y manera de argumentar tensa juicios e interpretaciones ${ }^{7}$, pero el que Las Casas tenga esa impropia fogosidad cara a las argumentaciones científicas no lo descalifica. En mi opinión estamos frente a un personaje ciertamente contradictorio y por demás exagerado en sus apreciaciones, lo que lo descalifica como historiador; sin embargo, cuenta con argumentaciones filosóficas importantes que contribuyen al discurso igualitarista internacional; en consecuencia, es indispensable ceder paso del horizonte histórico de comprensión de su pensamiento al plano de su antropologia social, pues de ella emergen sus consideraciones éticas, políticas y económicas.

Merece especial atención el tratado del Octavo remedio por su peculiar fuerza medieval, por centrarse en la bula papal que delega en los reyes de España la evangelización y por el tratamiento de cuestiones económicas. Otros tratados lascasianos se caracterizan por argumentar más al modo renacentista con razonamientos inspirados en Aristóteles y siguiendo a Tomás de Aquino, aunque bebiendo de una tradición ciceroniana y aristotélica más racional y humanista. Por ejemplo, en el famoso tratado Principia quaedam Las Casas establece cuatro principios que sirven de punto de partida a la controversia destinada a poner de manifiesto y defender la justicia de los indios, a saber:

1. Que la posesión de las cosas externas es justa y natural en el hombre.

2. Que el hombre reivindica para sí lo que es naturalmente suyo.

3. Que el dominio de las cosas inferiores al hombre le pertenecen en virtud del derecho de gentes.

7 Cfr. Díaz Aruajo, Enrique. Las Casas visto de costado (Madrid: Fundación Francisco Elías de Tejada y Erasmo Percopo, 1995). Allí el autor intenta probar que Las Casas carece de credenciales científicas mostrando las críticas y refutaciones que se han hecho de sus textos a lo largo del tiempo. En la misma tónica se encuentra el texto de Jean Dumont, El amanecer de los derechos del hombre. (Madrid: Encuentro, 2009). La obra es un intento de desenmascarar tanto al padre Las Casas como a sus seguidores; pero, en mi opinión, lo que tiene como telón de fondo es el rescate de la vía laical de Vasco de Quiroga y del clero secular frente al predominio dominico Lascasiano, y de las órdenes religiosas en general. Me aparto de textos como éste que, lejos de solucionar, polarizan. 
4. Que todo jefe espiritual o temporal de cualquier multitud está obligado a ordenar su régimen al bien común y a gobernar a sus súbditos de acuerdo a su naturaleza.

Allí, la deuda lascasiana con la Escuela de Salamanca es más clara, pero en el Octavo remedio sorprende en ocasiones el carácter canonista medieval de la argumentación, su separación del modo en que argumentan sobre el tema Francisco de Vitoria y Domingo de Soto. En el Octavo remedio, Las Casas no sólo incluye criterios filosóficos salmantinos y argumenta como aristotélico influido por el humanismo (cfr. Pol., I, 1257a 1-3; 1257b 12-16), sino que, al llevar la discusión al terreno moral, se centra en el escándalo encomendero por los lujos y avaricia, por la codicia y búsqueda ilimitada de ganancias económicas; ese discurso incendiario, radical, no argumenta con distinciones ni casos en los que la usura puede matizarse o distinguirse con el incipiente tema del interés, tal y como balanceadamente lo hacían los salmantinos. Lo que este artículo intenta probar es que Las Casas se acerca más a una idea veterotestamentaria del uso del dinero en la que se separa del criterio de la moral económica salmantina optando por el tema de la exclusión y la opresión de los más pobres e indigentes.

Las Casas, como muchos de los pensadores en América y al igual que Vasco de Quiroga, propone una organización económica basada en la agricultura más que en la minería. El criterio le viene como respuesta a las prácticas y tradiciones autóctonas en América y por la recuperación humanista de pasajes aristotélicos que defienden la economía doméstica como necesaria y alabada en detrimento de la crematística, censurada al no ser conforme a la naturaleza sino a expensas de los otros (cfr. Pol., I, 1258a 1-40). Como, para él, el bien común es el fin de la multitud, que consiste en el perfeccionamiento espiritual y social de los agrupados, los estamentos aristotélicos respondían a la articulación de los grupos sociales de la ciudad (así lo expresa en Apologética historia sumaria, obra que analiza la realidad indiana); de tal presupuesto parte para rechazar la minería como actividad que propicia la crematística y en cambio enaltecer la agricultura como actividad que responde a las necesidades domésticas para la vida (Pol., I, 1257a-1258b).

\section{ECONOMÍA EN LA ESCUELA DE SALAMANCA}

El tema de la economía en la Escuela de Salamanca presenta un tratamiento de transición frente al mercantilismo moderno. En especial, la idea de usura sobre cuestiones de intereses, préstamos y contratos mercantiles era considerada un pecado capital y no es sino tras el comercio con el Nuevo Mundo y el 
posterior surgimiento de los Estados nacionales que la usura es relegada por el principio del interés. El enfoque canónico previo se fundaba en los pasajes evangélicos de Lucas 6, 35 y Mateo 5, 42, que conectan la usura a una falta de equidad con escándalo para los pobres. Como sostiene González Ferrando ${ }^{8}$, la usura se consideraba un pecado contra el séptimo mandamiento, exigía restitución, rebasaba la justicia del precio en compraventa y era un asunto económico inseparable de la moral de acuerdo con los comentarios de Tomás de Aquino a la Política de Aristóteles y a la Suma Teológica, II IIae, q. 77-78. Estas argumentaciones serán una influencia profunda en la Escuela de Salamanca, en especial en Francisco de Vitoria y Domingo de Soto 9.

Durante muchos siglos los teólogos y monarcas católicos mantuvieron una identificación semántica entre dos términos que hoy consideramos diferentes, interés y usura. Fue así porque se entendió que toda ganancia obtenida por prestar dinero, era injusta y contraria a la naturaleza del mismo, pues desde Aristóteles se le había considerado como bien estéril o improductivo, expresando este carácter en el axioma nummus nummum non parit.

Autores como Vitoria en De iustitia, In II-IIae, q. 67-78 y Domingo de Soto en De iustitia et iure, L-VI, q. 1 a. 1, consideraron ilícita la usura; para ellos, en sentido estricto, la ganancia por préstamo de un capital era injusta ${ }^{10}$.

Lo explica bien Idoya Zorroza en su escrito Supuestos antropológicos en el tratamiento de la usura según Francisco de Vitoria ${ }^{11}$ cuando dice que hay una diferencia entre el enfoque medieval y moderno de la economía que refleja

un momento de clara transición por tres factores: a) el cambio en la consideración del dinero como fecundo de suyo, b) la consideración sobre si es necesaria la traslación del dominio junto con el uso en el préstamo pecuniario, c) la incorporación del tiempo como bien económico, siendo un bien externo a los agentes (Zorroza 2013, 19).

8 Cfr. J. M. González Ferrando, "La idea de usura en la España del siglo XVI. Consideración especial de los cambios, juros y asientos", Pecvnia 15 (2012): 1-57.

9 Cfr. José Barrientos García, Un siglo de moral económica en Salamanca (1526-1629). Francisco de Vitoria y Domingo de Soto (Salamanca: Universidad de Salamanca, 1985). El texto clave que inspira toda la argumentación es el tratado de la justicia (Cuestión 77, Sobre la compraventa y Cuestión 78, Sobre la usura) de Francisco de Vitoria.

10 Cfr. José María Garrán Martínez, "El concepto del préstamo y la usura en los maestros Salmantinos. Francisco de Vitoria y Domingo de Soto", Anales de Estudios Económicos y Empresariales 4 (1989): 130.

11 Cfr. Idoya Zorroza, "Supuestos antropológicos en el tratamiento de la usura según Francisco de Vitoria”, Cultura Económica 86 (2013): 19-30. 
El axioma que permea la argumentación tiene su raíz en que "prestar es un acto de liberalidad o fraternidad" (ibid., 20).

Se incluía también como referencia y autoridad a la tradición judeocristiana, la condena absoluta de cualquier práctica usuraria del Antiguo Testamento y los pasajes aristotélicos de la Política 1257b, 23, 1258b, 9; además, estaban las conclusiones vitorianas sobre la usura, que la consideraba una ruptura de lo justo conmutativo, lo que iba contra la equidad en el préstamo o contrato de mutuo, aquello prohibido por el derecho natural por razón del fin, esto es, la usura era "la causa de tantas incomodidades y angustias que se propagarían y se seguirían en la república" (Vitoria 2006, 143) ${ }^{12}$.

Es así que, en la tradición judeocristiana y en la salmantina, la usura se relacionó con un sentido instrumental del trabajo que en última instancia refería a un concepto esclavista del ser humano y a la supresión de la amistad en la vida política. Es Francisco de Vitoria quien abre las puertas para el discurso libertario lascasiano en pasajes donde argumenta que "si la usura fuera permitida, esto sería arruinar a los pobres, porque los ricos, si les fuera lícito dar usura, vaciarían todo el patrimonio de los pobres, y así los bienes se amontonarían en manos de unos pocos, y las ciudades incurrirían en graves pérdidas" (ibidem).

Como explican Zorroza y Barrientos, se aceptaba el daño emergente o por causas accidentales, pero no la concentración de suyo y por sí del capital. Pero, conforme el comercio se desarrolló en América, las prácticas a distancia fueron imponiendo nuevas reglas. Sin embargo, permeaba el criterio de la gratuidad del prestar: éste se consideraba un servicio a la comunidad ${ }^{13}$, ya que la intrínseca sociabilidad humana y el bien común de la república exigían la finalidad social. El préstamo no era un negocio, sino un servicio a la comunidad, un acto de justicia que crecía a quien lo practicaba y que estaba en el orden del beneficio y de la caridad para lograr la equidad. La causa final del bien común de la república estaba en la noción de amistad de la vida política, un punto clave en la comprensión del asunto que algunos especialistas han venido trabajando en textos de filosofía política salmantina como una tradición del siglo $\mathrm{XV}^{14}$. Sin embargo,

12 Citado por Zorroza, "Supuestos antropológicos en el tratamiento de la usura según Francisco de Vitoria", 23. Cfr. Francisco de Vitoria, Contratos y usura (Pamplona: EUNSA, 2006); Francisco de Vitoria, Comentarios a la Secunda Secundae de santo Tomás (Salamanca: Biblioteca Teológica Española, 1952); Idoya Zorroza, "Dominio y liberalidad según Francisco de Vitoria", Justicia y liberalidad (2012): 191-200.

13 Cfr. Zorroza, "Supuestos antropológicos en el tratamiento de la usura según Francisco de Vitoria", 23

14 Cfr. Cecilia Sabido, El pensamiento ético-político de Alfonso de Madrigal (Pamplona: EUNSA, 2016). Cfr. también Alfonso de Madrigal, Brevyloquyo de amor e amicicia (Pamplona: EUNSA, 2000); Pedro Martínez de Osma, Comentario a la Etica de Aristóteles (Pamplona: Universidad 
Bartolomé de las Casas radicaliza esta postura en el tratado del Octavo remedio $\mathrm{y}$, como veremos a continuación, ubica la discusión desde dos extremos: por un lado, en el poder encomendero que encarna en la Nueva España la ilegitimidad y voracidad ilimitada de concentración del capital; por otro, pone en los monarcas españoles la única posibilidad de legitimidad y restauración de los criterios políticos de la equidad republicana. Esta argumentación ya es distinta a la realizada por Vitoria y Soto, como veremos a continuación.

\section{EL OCTAVO REMEDIO Y EL TEMA DE LA AVARICIA Y USURA}

Las Casas dedica este tratado al rey de España, Carlos V. El texto es una petición a que el rey "jure formalmente por su fe, por su patria, por su real corona, y por todas las cosas sagradas que los príncipes cristianos tienen costumbre de jurar", que firme que "en ningún tiempo por su persona real ni por sus sucesores en estos reinos y en aquéllos revocarán esto" (Las Casas 1997, 645); se trata de la protección de los indios y del peligro que veía Las Casas por la opresión encomendera sobre ellos, incluso le pide al rey que ponga esa voluntad en su testamento. Las razones que da el dominico son veinte ${ }^{15}$; paso a exponerlas a continuación.

La primera, que tiene fuerza de principio, consiste en que los indios tienen que ser convertidos a la fe por expreso encargo divino y pontificio a través de los reyes de Castilla y León. Su inclusión en la Iglesia universal es una responsabilidad que no puede delegarse ni traspasarse a otro; tal responsabilidad implica que nadie, salvo los reyes, puede tener señorío ni dominio inmediato sobre los indios. La razón la da Las Casas diciendo que "Sólo personas reales pueden llevar esta tarea a cabo" (ibid., 649). El documento probatorio que menciona Las Casas es la bula de concesión de las Indias del pontífice Alejandro VI, que recomienda, en la primera parte, confianza en la fe, rectitud en el hacer y prudencia en el gobernar. En la segunda parte la cláusula da una recomendación formal con carácter prescriptivo y condicionado al decir que el pontífice "elige a la real dignidad y Corona de Castilla para que realice dicha tarea". En opinión del fraile, tal prescripción, al darse por propia voluntad, "devino en pacto originario por jurídica politización y por conveniencia obligatoria" (ibid., 653) ${ }^{16}$. Las cláusulas

\footnotetext{
de Navarra, 2002); Virginia Aspe Armella e Idoya Zorroza, Francisco de Vitoria en la Escuela de Salamanca y su proyección en Nueva España (Pamplona: EUNSA, 2016).

15 Cfr. De las Casas, "Octavo remedio", 646-851.

16 Debe notarse que Las Casas acierta en la interpretación jurídica del pacto originario, al grado que los discursos preindependentistas de México, a finales del siglo XVIII y comienzos del XIX, mantienen el argumento de que, quitado el Rey en la invasión napoleónica y dado el aprisionamiento
} 
significan que los Reyes de Castilla son inmediatos y directos administradores, y que la jurisdicción por derecho divino es intransferible; no se puede fiar ni delegar. Para probar la autoridad regia, Las Casas acude al ejemplo paradigmático de Isabel de Castilla, cuando en 1519 hizo regresar a Cristóbal Colón, a Bobadilla y a otros bajo el argumento de que nadie puede tomar por vasallos a los indios dado el pacto originario.

En la segunda razón, y basándose siempre en el primer principio establecido, Las Casas ubica el mayor estorbo para lograr que los reyes cumplan con el dicho fin: son los encomenderos ${ }^{17}$, por su gran avaricia y codicia. La argumentación posterior da ejemplos probatorios de su acusación: que los encomenderos no permiten que los indios estudien porque, si se hacen bachilleres, ya no realizarán trabajos manuales y bajarán las ganancias de los encomenderos; porque impiden que los religiosos entren a los pueblos para evitar que acusen a los encomenderos de sus atropellos; porque los encomenderos se exceden en exigir tributos y tasaciones a los indios; porque los encomenderos separan lo más preciado del género humano de los indios, que es vivir en pueblo y libertad conjuntamente.

Pasemos a analizar qué son la codicia y avaricia en Las Casas y cómo entiende que los españoles deben mantener a los indios en pueblo y libertad.

Sobre lo primero, la práctica de los vicios de la codicia y la avaricia, dice que los encomenderos tienen por estrategia "atemorizar a tal grado a los trabajadores que los tornen tímidos y pusilánimes", convirtiéndolos en "natura de liebres y hecho degenerar de ser hombres" (ibid., 661). Para Las Casas, la avaricia y la codicia consisten en "quitar lo propio de ser humanos". Lo primero que "hace humano" es "ser pueblo", evitando esparcir a la gente "quitando de vivir juntos social y popularmente". Lo segundo es "quitar la entera libertad". Las Casas acude a la tradición veterotestamentaria como autoridad principal diciendo que "el Dios de Israel en Egipto da a los hombres dos disposiciones, pueblo y libertad conjuntamente". Interpreta cómo es ese Dios: "un Dios, Yahvé, con mano válida y rigurosa, que los libertó y sacó del poderío tiránico del Faraón, rey de Egipto". He aquí el símil entre el pueblo elegido de Dios con la tiranía poderosa del Faraón frente a la realidad indiana y el poder tiránico encomendero $^{18}$. Se trata del Éxodo del Pueblo de Dios, un peregrinaje doloroso para evitar la opresión egipcia; la interpretación tiene también ecos de la Ciudad de Dios de san Agustín (Prólogo y L. I-1). Y es que el dominico recurre a dos tradiciones

de Fernando VII, la Nueva España se encuentra en estado de interregno; incluso algunos discursos preindependentistas dan la solución de que el poder regresa al pueblo o al Ayuntamiento.

17 Cfr. De las Casas, "Octavo remedio", 657.

18 Cfr. De las Casas, "Octavo remedio", 665. 
que articulan su visión desde el universo pagano: la tradición veterotestamentaria, que opone la imágen de Moisés con las Tablas de la Ley a la adoración del pueblo de un becerro de oro, y la imagen agustiniana de una ciudad de Dios frente al desorden del apego mundano.

Quedan establecidas en las dos primeras razones del Octavo remedio las consideraciones libertarias y emancipadoras del discurso económico fundacional americano. Para Las Casas, el Dios del Antiguo Testamento garantiza la noexclusión. Intérpretes del tema de la usura sostienen que sólo en la tradición hebrea se consideró a la usura radicalmente perversa y que cuando ésta fue aceptada se debió a una prescripción de derecho positivo divino para evitar males mayores. En la tradición medieval oriental, la usura fue regulada para mantener la equidad y, aunque en la tradición medieval latina ésta fue rechazada, matizó paulatinamente su sentido hasta que, en el siglo XVI, hace distinciones de tiempo, lugar e incluso por porcentajes ${ }^{19}$; sólo la tradición hebrea fue radical en este punto y Las Casas se adhiere a ella para hacer una brecha tajante entre ambas realidades: la encomendera y la indiana. La razón está en que, en el Antiguo Testamento, Yahvé se entiende como Dios eminentemente justo, que se enoja y radicaliza frente a la opresión de los pobres y más necesitados; en esto, Yahvé es un Dios inclemente ${ }^{20}$. Investigadores latinoamericanos actuales han detectado esta opción preferencial de los frailes del siglo XVI novohispano para argumentar sobre las injusticias de los encomenderos en contra de los indios oprimidos ${ }^{21}$.

De inspiración marxista, autores como Boaventura de Sousa Santos o Enrique Dussel, y otros de inspiración personalista cristiana que siguen a Emmanuel Mounier, como es el caso de Efraín Gonzalez Morfín, retoman los pasajes lascasianos para probar un personalismo comunitario y solidarista que pretende ir construyendo una sociedad inspirada en la comunidad Trinitaria: las relaciones sociales de los hombres a imagen de las personas en Dios son Uno y Trino ${ }^{22}$. Lo

19 Cfr. González Ferrando, "La idea de usura en la España del siglo XVI", 1-57 y Barrientos García, Un siglo de moral económica en Salamanca (1526-1629).

20 Desarrollo este análisis en Virginia Aspe Armella, "The influence of the School of Salamanca in the Treaty about Dominion of the Unfaithful and the Fair War: First relectio in America by Alonso de la Veracruz", artículo en proceso de publicación, Brill, 2019.

21 Por ejemplo, Jesús Antonio de la Torre Rangel y también Mauricio Beuchot. El tema lo ha desarrollado especialmente Enrique Dussel. Cfr. Jesús Antonio de la Torre Rangel, Del pensamiento jurídico contemporáneo. Aportaciones críticas (San Luis Potosí: UASLP, 2006): 208- 239.

22 El discurso deambula entre propuestas jurídicas de corte histórico hasta algunas francamente teológicas. Sugiero acudir a los siguientes autores: Boaventura de Sousa Santos, Por una concepción multicultural de los derechos humanos (Ciudad de México: UNAM, 1998); Enrique Dussel, Filosofia de la liberación (Ciudad de México: Edicol, 1977), 11-22; Enrique Dussel, Humanismo semita (Buenos Aires: Universidad de Buenos Aires, 1969), 49-154; José Luis Sicre, Con los pobres de la Tierra. La justicia social en los profetas de Israel (Madrid: Cristiandad, 1984); De la Torre Rangel, Del pensamiento jurídico contemporáneo (San Luis Potosí: UASLP, 2006), 239 y ss. 
que argumentan esas interpretaciones es que Las Casas instaura un iusnaturalismo de enfoque histórico que defiende el derecho a la disidencia y una filosofía de la liberación que retoma de la tradición profética lo relativo al modo de entender el derecho con el término hebreo bíblico de mispat: liberar de la injusticia a los oprimidos. Su tesis es que en la tradición veterotestamentaria, la justicia se refiere a quien padece injusticias en orden al bien común, donde su contrario es el mal común que padece la mayoría. En esto Bartolomé de las Casas lleva el tema de la avaricia y usura al terreno de la justicia distributiva cuando en los salmantinos como Vitoria la usura se opone a la justicia conmutativa porque le precede un contrato e implica restitución. Pero, para el padre Las Casas, el planteamiento ha de hacerse desde la oposición al bien de la comunidad por la exclusión y opresión de los grupos más necesitados. Lo que está de tela de fondo en la discusión es la esencia misma de lo que significa la encomienda, algo distinto a la contratación entre pares ${ }^{23}$.

Son muchos los pasajes del Octavo remedio que ilustran este rompimiento de la equidad; pongo de ejemplo el que dice: "sudores, angustias, hambres, sedes, andando por sierras, caminos largos, trabajo sin vestido, miedo (...)" (Las Casas $1997,659)^{24}$, texto que, si se equipara con la consideración de la codicia del encomendero, se hace más radical. Por estas vejaciones surge la radicalización de la postura lascasiana:

(...) de la misma manera ya dicha, dar los indios en poder de los españoles, que es fiar las gargantas de los hijos en las manos ocupadas con navajas de los frenéticos, es poner los hombres en poder de los furiosos capitales enemigos y que muchos días haya que con mucha ansia lo desean (ibid., 723).

Es obvio que la relación entre la teología de la liberación y el discurso lascasiano debe ser matizada, pues los pasajes bíblicos no sólo hablan de temas económicos, sino de injusticias en general. Sin embargo, hay ciertas características del pensamiento de los profetas en Las Casas que, analizadas, muestran la evolución que sufrió el pensamiento del dominico y la manera en que desplazó su discurso hacia la emancipación económica. Tales características, similares a la idea veterotestamentaria señalada son, según la acertada interpretación de De la Torre Rangel, su profunda ubicación histórica al enfrentar los problemas de justicia, la palabra historizada, el énfasis en la injusticia a los más vulnerables, la conexión de la justicia con el pecado y la denuncia, el enfoque religioso del

23 Cfr. Francisco De Vitoria. Contratos y usura (Pamplona: EUNSA, 2006), especialmente Cuestión 77, Sobre la compraventa y Cuestión 78, Sobre la usura, 136-146.

24 Mantiene un mismo discurso en Historia de Indias. Cfr. Bartolomé de las Casas, Obras completas, 29-30. 
problema, y el que Yahvé tenga como interlocutor al pueblo. Estos elementos son distintivos en Las Casas, como veremos a continuación.

La tercera razón del Octavo remedio dice que los españoles no son capaces de encomendar e introduce otro elemento esencial a la tesis emancipatoria: el uso instrumental de las personas. La noción de "instrumento" es uno de los conceptos más importantes de cara a la liberación de América. Por "instrumento" Las Casas entiende lo contrario a lo humano. Recordemos que, para el dominico, si lo contrario a lo humano es quitar pueblo, es decir, quitar la sociabilidad haciendo que se disperse la gente por los bosques y ande errante, lo es también su sujeción forzada al reducirlos a trabajos de carga o serviles. El uso instrumental implica la consideración de los indios como medios de utilidad extrínseca. Las Casas define lo humano como lo que es fin en sí mismo, capaz de autodominio; en cambio, el carácter instrumental del trabajo es la suspensión de la esencia humana ${ }^{25}$.

Continúa sus razones reiterando lo dicho para, en la sexta razón, profundizar más el significado de instrumento al decir que "los españoles son hostes" ${ }^{26}$ significando con ello "lo contrario a la guerra, hospedar". Pero "hostes" significa "al ejército o parte de él en la guerra" 27 . Las Casas juega con esta ambivalencia terminológica, logrando una profunda penetración de lo que significa la encomienda: tener por encargo, acoger, albergar, recibir en una situación de emergencia bélica o impuesta. Llama "hostes" a los encomenderos y en seguida les dice "enemigos capitales de toda su generación". Así, el término tiene que ver con hostilidad en lugar de con acogida, y lo relaciona a la noción de instrumento: aquéllos que, en lugar de recibir y considerar igual al otro en cuanto vidas cuyo ser es fin en sí mismo, recibiéndolas en condiciones de igualdad, hacen lo contrario, usándolas exclusivamente para alguna utilidad económica o mercantil.

La ambivalencia del término se amplía en la razón séptima, una de las más relevantes para nuestro análisis.

\section{LAS PARADOJAS EN LA CONSIDERACIÓN DE LA RIQUEZA EN LAS CASAS}

Las Casas dice que nunca se debe dar regimiento a hombres pobres ni codiciosos, y menos a los que anhelan ser ricos, pues, al tener deseos de salir de la pobreza, caen en avaricia. No queda claro su concepto de pobreza y menos

25 Para Las Casas, ser humano es ser fin en sí mismo. Cfr. Bartolomé de las Casas, Del único modo de atraer a todos los pueblos a la verdadera religión (Ciudad de México: FCE, 1975).

26 Cfr. De las Casas, "Octavo remedio", 689.

27 Diccionario de la Real Academia de la Lengua: término hostes. 
cuando ha abierto la puerta a un gobierno exclusivamente regio ya que, aunque considera que sólo la pobreza unida a la codicia es perversa, dice que la bondad de los reyes radica en que, por poseer bienes económicos, no caen en el vicio de la codicia, pudiendo gobernar con mayor libertad. Es verdad que sólo es culpable una pobreza atada a vicios, pero, aunque no diga que todo pobre deviene en codicioso, a la hora de juzgar a los peninsulares y otorgar todo el poder a los monarcas, atribuye a las clases bajas e iletradas mayor probabilidad de caer en ese vicio. La interpretación se opone a la bonanza económica como bien en sí y queda claro que la paideia lascasiana hará de la desposesión material una virtud o un vicio: según si se recibe opresión y despojo, virtud, pero si se es codicioso, vicio; entiende la pobreza no en el sentido en que el cristianismo defiende la diversidad de niveles económicos en la comunidad como una realidad de facto, sino en cuanto ideología emancipadora: un signo de bondad es recibir opresión, y Yahvé clama desde el cielo para que ésos queden liberados. Es la contraparte de la teología calvinista en lo económico, donde un signo de beneplácito divino es la riqueza en la tierra; aquí, en cambio, Yahvé está más cerca de los oprimidos al tiempo que no tener riqueza presenta el peligro de encandilarse con el lujo y las posesiones de otros, por lo que ser virtuoso implica alejarse del lujo y afán de posesión. En todo caso, la riqueza de suyo es puerta del vicio, la pobreza puede llevar a la ambición y la opresión recibida por los poderosos es signo de estar cerca de un Dios que es clemente y que se encoleriza ante los opresores de vulnerables e indigentes.

Las Casas define la riqueza como algo ilimitado, ya que el apetito y la codicia "siempre tienen como fin la riqueza y mientras que no alcance ese fin es insaciable", pero dice que "la naturaleza rehúye a la riqueza, como lo vacío a lo vacío, por no lo poder sufrir". Explica que el problema de la riqueza es que "trátase de una realidad ilimitada, infinita en su deseo, más se tiene más se desea"; dice: "el codicioso es adicto a un fin nunca saciado, todas sus fuerzas, maneras e industrias, toda su creatividad e inventiva, es llenar ese vacío” (ibid., 703).

\section{LA CODICIA EN EL PADRE LAS CASAS}

Pasa a analizar la codicia. Su primera fuente es también veterotestamentaria, aunque expande el planteamiento, retomando De Consolatione III, de Boecio, al decir que el apetito de ser rico en el pobre y codicioso es semejante al apetito total de la bienaventuranza porque, así como "la bienaventuranza promete ser el bien-amado por sí suficiente y no faltalle nada, así las riquezas prometen por sí suficiencia". Homologa el deseo de riqueza y codicia a "sanguijuelas en el cuerpo humano cuyo único fin es chupar y embeber en sí la substancia de todo 
el pueblo" (ibidem). Recordemos que la metáfora entre chupar la sangre y la injusticia está presente desde el Antiguo Testamento ${ }^{28}$. Describe el fenómeno de la codicia haciendo una analogía con la metáfora previa:

(...) es por fuerza que pudiendo han de cumplir y satisfacer a su natural apetito para alcanzar el fin que pretenden (...) aunque sea un riesgo de todos aquéllos sobre los que tienen jurisdicción o mando, especialmente si de ellos y de otra parte saben y ha de venirles, porque el vacuo o vacío del apetito de ser de los hombres codicioso ricos, no se puede henchir jamás en esta vida, porque el fin de haber riquezas no tiene jamás término.

Cita una vez más autoridades veterotestamentarias, aquí Eclesiastés, 5, "avarus non implebitur pecunia..., mal insanable por ninguna cura humana" (ibid., 705). Y es que según su interpretación, la codicia no es curable porque la posesión de la riqueza es como la bienaventuranza y la felicidad: la autosuficiencia de ambas tiene razón de fin. He aquí el señalamiento del peligro lascasiano y su rechazo a la riqueza, porque deviene fin en sí misma, siendo que es algo material y que, en consecuencia, tendría que tener término. Aunque no es así, porque la riqueza parece representar la cúspide material de la bonanza. Y como su fin es apetecible y deseable ilimitadamente, el apetito y deseo del codicioso es infinito y lo hace vehemente; por tanto, el vacío del apetito jamás puede llenarse.

Las Casas hace una similitud entre el dinero y la bienaventuranza: por su semejanza, el alma pierde su centro al poner el fin en el dinero y sigue buscando infinitamente el objeto deseado. En un juego de espejos, el dinero se convierte en una posibilidad de aumento y mejora de infinitos. La naturaleza del dinero hace que entre más aumente la riqueza del que la tiene, menos se sacie. Cada vez es más intenso su sentimiento de no lograr acceder al fin y, por ello, crece más su apetito ${ }^{29}$.

Por último, entra al tema concreto que relaciona el dinero con la circunstancia indiana: los tributos ${ }^{30}$. Recordemos que el tema del pago de tributos fue el que enfrentó a las ordenes mendicantes con la administración colonial. Autores tan diversos como Alonso de la Veracruz y Bartolomé de las Casas

28 Pasajes del Antiguo Testamento que conectan con el tema: Jeremías 9, 23: "Tu padre comió y bebió, practicó la justicia -sadaqá- y el derecho -mispat-y le fue bien; hizo justicia a pobres e indigentes y eso sí que es conocerme... Tú, en cambio, tienes ojos y coraza sólo para el lucro, para derramar la sangre inocente". Citado por De la Torre Rangel, Del pensamiento jurídico contemporáneo, 227. Otros pasajes que merecen destacarse: Absalón 5, 2-4; Deuteronomio 23, 20; Amós 1, 3-2; 5-24; Isaias 1, 10-17; Jueces 5, 22-25.

29 Cfr. De las Casas, "Octavo remedio", 707 y ss.

30 Cfr. De las Casas, "Octavo remedio", 737-740. 
abordaron el tema en sus escritos ${ }^{31}$. Consistente con la importancia que concede a los reyes españoles y a los documentos fundacionales pontificios e isabelinos, Las Casas acepta los tributos al rey diciendo que son por derecho divino al servir para la evangelización, pero rechaza los tributos que exigen los españoles a los indios y los pagos de estancieros. Aclara que los indios ya pagan tributo a sus caciques por acuerdo de las Leyes de Indias; reitera que los tributos al rey tienen además el fin de aportar servicios a la república, aunque señala que aun el rey no puede pedir tributos extraordinarios a los indios. El principio con el que argumenta es el de "ne gravetur duplici onere", que implica que se va contra la justicia cuando se duplican o exceden los tributos. Niega toda posibilidad de que los encomenderos cobren tributos a los indios ${ }^{32}$ y lo explica: las únicas servidumbres que pueden constituirse son las necesarias a la república, lo que implica que son por acuerdos comunes o de derecho de gentes y que, si se oponen a esto, van contra la caridad y la justicia al pretender que unos seres humanos lleven las cargas de otros para su comodidad. Y conecta la tradición hebrea con la neotestamentaria citando Mateo, 7; a Pablo en Gálatas 5 y 6, y a Pablo en Romanos, 13 , concluyendo que esto es así para que no sean más afilados con tantas cargas, lo que va contra la caridad y la justicia.

Entra en la novena razón recordando el documento jurídico que avala su propuesta, aunque justifica el pago de impuestos regios, tema que me parece importante resaltar porque dice que esto se debe a que los reyes tienen "oficio de apóstoles" (ibid., 745) en franco acercamiento integrista de su propuesta política que refuerza cuando sostiene que son los obispos los que habrían de supervisar estos pagos. Continúa sus razones diciendo que el criterio responde a que en el oficio regio se cuenta con mayor suavidad, pronta liberalidad de voluntad para respetar a quienes deseen recibir la fe y no imponerla. Las Casas dice que los reyes son los que respetarán la voluntad de conversión o no de los indios, así que centra la garantía de esta cuestión en el principio regio. Aclara que no se pueden traspasar los bienes ni donar vasallos en traspaso, que sólo puede tenerse un solo señor, el rey; llega incluso a decir que los pueblos tienen por agravio ser privados de inmediato de señor y jurisdicción real ${ }^{33}$. Se trata, en consecuencia, de un sistema vertical en el que a la cúspide está la donación pontificia y de allí surge el regio legado, que no se cuestiona ${ }^{34}$. La donación regia queda justificada si se garantiza el bien común del pueblo; aclara que esto se justifica siempre y cuando el monarca respete los límites de su poder, ya que "el 2007).

31 Cfr. Alonso de la Veracruz, De dominio infidelium et iusto bello (Ciudad de México: UNAM,

32 Cfr. De las Casas, "Octavo remedio", 739.

33 Cfr. De las Casas, "Octavo remedio", 749.

34 Cfr. ibidem. 
príncipe no puede hacer nada que venga a hacer perjuicio para los pueblos" (ibid., 751). Las Casas vislumbra un gobierno tradicional que debe seguir las pisadas de los Reyes Católicos, aunque concede cierto corte republicano por condicionar al príncipe a servir a los pueblos y porque le recuerda que ha de convocar a las cortes y hacer venir a procuradores; es aquí donde se aparta de tener una solución integrista.

Llama la atención la décima razón, pues, a manera de conclusión del argumento, dice que el rey puede quitar jurisdicción al que haga mal uso de sus tareas, ya que las leyes de Castilla son emanadas directamente del privilegio del rey. Y sorprende, porque antes había sostenido que el rey no había dado encomiendas ni permisos de tributos, pero la sentencia es para darle al rey poder de cambio en las jurisdicciones frente a quien sea que las haya otorgado. Por eso termina la disertación con las siguientes razones, diciendo que la encomienda no se hizo con autoridad de los reyes y que ésta debe suspenderse por los efectos que tiene en los indios, porque violan el Consejo Real y los acuerdos teológicos y porque, por caridad y magnanimidad real, esto debe llevarse a cabo ${ }^{35}$.

\section{BALANCE DE LA TRADICIÓN SALMANTINA EN AMÉRICA Y LAS APORTACIONES LASCASIANAS AL TEMA DE LA ECONOMÍA}

En Historia de las Indias (1517), obra que acompaña toda la vida de las Casas, y en la Brevísima historia de la destrucción de las Indias (1552), se gesta un discurso emancipador que se corona en el Octavo remedio contraponiendo la codicia de los encomenderos con el universo indiano al que ubica en la Edad de Oro (Brevísima 15) argumentando que, “(...) en ellos no hay lujo ni vicio de posesión". En Brevísima 17, equipara a los españoles con "lobos e tigres y leones cruelísimos" mientras que los indios están hambrientos. Presenta dos tipos de hombres que responden a dos universos distintos, el español y el autóctono ${ }^{36}$. Y da una única solución: poner todo el peso de la respuesta en el poder regio condicionado por la cesión pontificia de América. No es objeto de este escrito analizar la concepción política lascasiana heredada de Francisco de Vitoria, pero cabe mencionar que en De potestate civili Vitoria se había acercado a la noción de Estado moderno laico al defender el poder político como humano. Empero, en sus comentarios a la II-IIae, q. 52, art. 2, parece que Vitoria se acerca al absolutismo en la medida en que enfatiza que el poder del monarca le viene de

35 Cfr. De las Casas, "Octavo remedio", 800 y ss.

36 No se entienda este pasaje a la luz de la historia sino en cuanto modelos o clases de hombres: como oposición entre la crematística individual y el bien común de los pueblos sometidos. 
Dios. Especialistas del tema discuten la supuesta ambigüedad vitoriana en el asunto $^{37}$.

Autores como Maravall, Ferraioli y Urdánoz debatieron sobre si para Vitoria el sujeto del poder político es el monarca o si la naturaleza civil y social del poder está en la república. En mi opinión Vitoria opta por la segunda interpretación y no hay ambigüedad en el asunto, el problema es que, para lograr este punto en el caso concreto de Nueva España, tiene que enfatizar el poder del rey por la donación de Alejandro VI y ulterior encargo a los monarcas españoles. Bartolomé de Las Casas parte de esta interpretación vitoriana para justificar la autonomía de los pueblos indios cara a la errada interpretación de las encomiendas.

Además de esta interpretación política, conviene recordar que sería imposible valorar esta propuesta sin tomar en cuenta las tradiciones que sigue Las Casas al argumentar sobre el asunto: un énfasis retórico para persuadir a la reordenación del orden colonial, énfasis heredado del humanismo que bebe de las cátedras de gramática y retórica con apoyo de la exégesis bíblica de los hebraistas judaizantes de la Universidad de Alcalá, la orientación positiva de la teología en detrimento de la especulativa; el afán pedagógico y la noción renacentista de universalidad del género humano; el recurso a los loci que formula argumentos desde "clases de hombres" y no desde individuos específicos, y la conexión entre ley y moralidad. Salvo por el método de los loci, todas estas características las plantea acertadamente Belda Plans sobre los autores salmantinos, aunque se presentan radicalizadas en Las Casas $^{38}$. La particularidad de Las Casas está en la consideración de que la raíz de todos los males americanos es la avaricia de los encomenderos, por lo que debe cancelarse el estado de facto de las encomiendas; en esto se distingue de la tradición salmantina ${ }^{39}$.

Es entonces que comienza a citar pasajes veterotestamentarios, como Jeremías 22, 17: "Mas tus ojos y tu corazón no son sino avaricia y derraman sangre inocente, y a opresión y a hacer agravio". Como en Ezequiel 22, 27, "Sus ojos en medio de ellos como lobos que arrebatan presa, derramando sangre, para destruir las almas, para seguir su avaricia". Emula la avaricia española con la idolatría del becerro de oro de Exodo, donde Moisés rompe las Tablas de la Ley ante la visión de una comunidad que pone el oro por encima del Dios verdadero. El fin que persigue es la reordenación del poder económico en la administración

37 Un texto que expone la generalidad del problema es: Leopoldo José Prieto López, "La soberanía en Vitoria en el contexto del nacimiento del Estado Moderno: algunas consideraciones sobre De Potestate Civili de Vitoria". DOXA, Cuadernos Filosóficos del Derecho, 40 (2017): 223-242.

38 Belda Plans, ibid., 98-105.

39 Cfr. Las Casas, Tratados, 707 y ss. 
colonial. Promueve -como lo había dicho Francisco de Vitoria en su obra De potestate Ecclesia posterior - que los obispos sean los que supervisen el pago de tributos, separándose ambos de Tomás de Aquino en este punto. Las Casas desarrolla más ampliamente el tema de la restitución en otras obras, por ejemplo, en el Memorial de los remedios cuando, basado en el texto bíblico de Eclesiastés 34 , niega la absolución a aquellos encomenderos que no restituyan lo aventajado sobre los indios ${ }^{40}$.

Pero el objetivo de fondo del Octavo remedio es una cuestión de justicia distributiva: el derecho del pobre, de los grupos vulnerables. Lo que es de notar es que Las Casas sigue a Francisco de Vitoria en los vuelcos a pesar de radicalizar la propuesta y tener un discurso afectado frente a la realidad concreta, realidad que Vitoria analizaba con equilibrio y sobriedad mediante la precisión de la lengua y el discurso. Aunque la distancia entre Vitoria y Las Casas es grande en cuanto a forma y estilo, un análisis detenido de los contenidos los mantiene cercanos. Es evidente que el discurso emancipador de la economía lascasiana no puede interpretarse exclusivamente desde criterios marxistas, amén del anacronismo que se cometería; Las Casas parte de un criterio tomista de persona y ése es el principio con el que argumenta las violaciones a la justicia. Pero el fraile radicalizó su postura después de la implementación de las Nuevas Leyes de 1542; en los siguiente años, el poder encomendero recrudeció sus embates, en especial contra Las Casas después de la disputa de Valladolid (1550-1551); los encomenderos peruanos hicieron una petición de jurisdicción y perpetuidad de tenencia y, en la Nueva España, los problemas con los hijos de conquistadores se recrudecieron. En opinión de David Brading, Las Casas comienza allí una línea más radical, aproximándose a canonistas medievales ${ }^{41}$. Empero, mantiene las tesis salmantinas fundamentales: la definición de justicia conmutativa, el principio tomista de que la potestad del Sumo Pontífice es espiritual, la subordinación de la economía a la política y la primacía del bien común sobre el individuo. Pero otorga mayor fuerza al argumento de que la donación papal es legítima, enfatizando más su enfoque modal, es decir, que la donación estaba condicionada a que la evangelización se llevara a cabo adecuadamente para la defensa de la protección indiana como parte del universo cristiano. Al elaborar la serie de tratados jurídicos de 1552, Las Casas articula la defensa de la autonomía política de los caciques indios para eximirlos del pago de tributos y cobros, y comienza su denuncia de la codicia de encomenderos articulando un discurso diverso al de los teóricos salmantinos ${ }^{42}$.

40 Cfr: Brading, Orbe indiano, 75-76.

41 Cfr. Brading, Orbe indiano, 114.

42 Cfr. Brading, Orbe indiano, 114-121. 
Este discurso emancipador de Las Casas tiene la grandeza de la alteridad y la capacidad de observar la sangre de los otros y de denunciar la violencia que ejerce la codicia; empero, sólo puede comprenderse con plenitud si se entiende la analogía medieval que practicaba la Escuela de Salamanca. Aparece aquí la relevancia de la formación salmantina del fraile. En sus aportaciones se exige la metodología comparativa textual de sus obras, ya que Las Casas es un autor que tiene un único mensaje desde el inicio de su producción, a pesar de la evolución de su pensamiento y de que opta por distintas tradiciones según las exigencias del momento. En dos textos relevantes para nuestro tema, Mauricio Beuchot retoma el método tomista y cayetaniense de la analogía que siguieron los salmantinos, y llama la atención sobre la necesidad de entender el realismo analógico como un concepto de verdad entendido como correspondencia proporcio$\mathrm{nal}^{43}$. La prueba de esta herencia escolástica en Las Casas es su obra Apologética historia sumaria (1542), escrita antes de los tratados filosóficos.

\section{CONCLUSIÓN}

Es indudable que Bartolomé de las Casas es deudor de la tradición en la que fue formado, la hoy denominada Escuela de Salamanca. El haber participado del currículo de la universidad y de la cátedra de sus maestros le aporta el andamiaje de filosofía jurídica propio de dicha tradición; a pesar de ello, Las Casas no cita a los maestros salmantinos en el Octavo remedio. Otros autores, como Alonso de la Veracruz, pudiendo haber citado muchas de las tesis y autores salmantinos, tampoco lo hicieron. El hecho merece repensarse y formular la pregunta de por qué se separan explícitamente de ellos; en esto queda clara la clasificación de Belda Plans sobre los novohispanos como grupo de "tercera generación de la Escuela de Salamanca" separándolos del resto.

Bartolomé de las Casas articula un discurso emancipador más radical que el de De la Veracruz y otros religiosos en América que se oponían a los excesos de la administración colonial, quizás debido a las circustancias que vivió por la experiencia americana, quizás por la convicción que tenía de fundar una república autóctona subordinada a los poderes regio y pontificio, alejada de la administración hispánica. Lo cierto es que, en el claroscuro de la emergencia, que respondía a los hechos por las prácticas de los encomenderos, el dominico articula una

43 Cfr. Mauricio Beuchot, Tratado de hermenéutica analógica (Ciudad de México: UNAM, 1997); Mauricio Beuchot, Derechos humanos. Historia y filosofia (Ciudad de México: Fontamara, 1999). 
argumentación más radical a la desarrollada por los tratados españoles de su tiempo, desplazándose hacia la tradición antigua de los profetas de Israel.

\section{REFERENCIAS BIBLIOGRÁFICAS}

Aspe Armella, Virginia y María Idoya Zorroza. Francisco de Vitoria en la Escuela de Salamanca y su proyección en Nueva España. Pamplona: EUNSA, 2014.

Barrientos García, José. Un siglo de moral económica en Salamanca (1526-1629). Francisco de Vitoria y Domingo de Soto. Salamanca: Universidad de Salamanca, 1985.

Belda Plans, Juan. La Escuela de Salamanca. Madrid: BAC, 2000.

Beuchot Puente, Mauricio. Derechos Humanos. Historia y Filosofia. Ciudad de México: Fontamara, 1999.

- Estudios de historia y de filosofía en el México colonial. Ciudad de México: UNAM, 1991.

—. Tratado de hermenéutica analógica. Ciudad de México: UNAM, 1997.

Brading, David. Orbe indiano. De la monaquía católica a la república criolla. 1492-1867. Ciudad de México: FCE, 2003.

De la Torre Rangel, Jesús Antonio. Del pensamiento jurídico contemporáneo. Aportaciones críticas. San Luis Potosí: UASLP, 2006.

De la Veracruz, Alonso. De dominio infidelium et iusto bello. Editado por Roberto Heredia Correa. Traducido por Roberto Heredia Correa. Ciudad de México: UNAM, 2007.

De las Casas, Bartolomé. Del único modo de atraer a todos los pueblos a la verdadera religión. Ciudad de México: FCE, 1975.

-. Obras completas. Editado por Paulino Castañeda Delgado. XIV vols. Sevilla: Alianza, 1989-1999.

- Obras completas. Editado por Paulino Castañeda Delgado. XIV vols. Madrid: Alianza, 1988 - 1996.

—. "Octavo remedio". En Tratados, 643-837. Vol. II. Traducido por Agustín Millares Carlo y Rafael Moreno. Ciudad de México: FCE, 1997.

De Madrigal, Alfonso. Brevyloquyo de amor e amicicia (1437-1444). Editado por Nuria Belloso. Pamplona: EUNSA, 2000.

De Sousa Santos, Boaventura. Por una concepción multicultural de los derechos humanos. Ciudad de México: UNAM, 1998.

De Vitoria, Francisco. Comentarios a la Secunda Secundae de Santo Tomás. Salamanca: Biblioteca de teólogos españoles, 1952.

-. Contratos y usura. Pamplona: EUNSA, 2006.

Díaz Araujo, Enrique. Las Casas visto de costado. Crítica bibliográfica sobre la Leyenda Negra. Madrid: Fundación Francisco Elías de Tejada y Erasmo Pèrcopo, 1995. 
Dussel, Enrique. Filosofia de la liberación. Ciudad de México: Edicol, 1977.

-. Humanismo semita. Buenos Aires: Universidad de Buenos Aires, 1969.

Garrán Martínez, José María. "El concepto del préstamo y la usura en los maestros salmantinos. Francisco de Vitoria y Domingo de Soto". Anales de Estudios Económicos y Empresariales (1989): 123-132.

González Ferrando, J. M. "La idea de "usura" en la España del siglo XVI: consideración especial de los cambios, juros y asientos". Pecvnia 1 (2012): 1-57.

López Vela, Valeria. Igualdad, libertad y legalidad. Reflexiones políticas sobre filosofía lascasiana. Ciudad de México: Porrúa, 2014.

Martínez de Osma, Pedro. Comentario a la Ética de Aristóteles. Pamplona: Universidad de Navarra, 2002.

Mártir de Anglería, Pedro. The Discovery of the New World in the Writings of Peter Martyr of Anghiera. Editado por Ernesto Lunardi, Elisa Magioncalda y Rosanna Mazzacani. Traducido por Felix Azzola. Roma: IPZS, 2004.

Sabido, Cecilia. El pensamiento ético-político de Alfonso de Madrigal. Pamplona: EUNSA, 2016.

Sicre, José Luis. Con los pobres de la Tierra. La justicia social en los profetas de Israel. Madrid: Cristiandad, 1984.

Zorroza, Idoya. "Dominio y liberalidad según Francisco de Vitoria". En Corso, Laura e Idoya Zorroza, Justicia y liberalidad. Antecedentes medievales y proyecciones en el Siglo de Oro, 191-204. Pamblona: EUNSA, 2012.

- "Supuestos antropológicos en el tratamiento de la usura según Francisco de Vitoria". Cultura Económica (2013): 19-30.

Virginia Aspe

Facultad de Filosofía

Universidad Panamericana

Augusto Rodin 498, Insurgentes Mixcoac 03920 Ciudad de México (México) https://orcid.org/0000-0002-0685-7721 